\title{
Rolling up our sleeves
}

Stephen Hancocks OBE

Editor-in-Chief

The BDJ Upfront section includes editorials, letters, news, book reviews and interviews. Please direct your correspondence to the News Editor,

Kate Quinlan at k.quinlan@nature.com. Press releases or articles may be edited, and should include a colour photograph if possible.

S trange how history weaves its course. At one time, the entreaty to 'roll up your sleeves' would have been interpreted as getting on with a particular job or task, akin to expressions such as shoulders to the wheel or noses to the grindstone. Now, in these early weeks of 2021, it has quite a different connotation as we prepare in an orderly succession to receive our vaccinations against coronavirus. I am not proposing to re-rehearse the debate here as to the brilliance of the speed behind the science, the pluses and minuses of tiers and lockdowns early or late, or the organisation of the vaccination process as these are well debated elsewhere, even if not, for now, over a pint of beer in the local pub. There will be a time for this to which we all look forward.

What I would like to touch on is the excellent news that, at the time of writing, NHS England has confirmed that all dentists, teams and support staff in both NHS and private settings will receive priority access to the COVID-19 vaccine. I am sure that the other nations in the UK will follow this lead. As well as providing the obvious immunological protection, this move also serves to support government and societal regard for dentists and dental team members as an integral part of healthcare. This has not necessarily been the unequivocally clear message to date, as dental team members have been excluded as 'key workers' and thus denied by default benefits such as assistance with childcare during the pandemic. This change should now help to strengthen the value rightfully placed on the central role of oral health in general health and the coronasafety of dental practices and dental treatment. I note here that despite two previous mentions I have still not been made aware of any cases of coronavirus infection being tracked or traced to the provision of dental care, either for patients or dental team members. If this is the case then it is a remarkable testament to the robustness of our cross-infection control measures and the science behind them, and should be applauded.

Additionally, the inclusion of dental team members in administering the vaccination programme is a great boost to the roll-out of the process. It also underlines many of the experiences reported throughout last year's redeployments, during which the value of dental members as part of the wider interdisciplinary health workforce was appreciated as never before. Long may this continue and be seen as at least one positive from an otherwise bleak period in our personal and professional histories.

What is striking about the pandemic is the way in which the changes in our living patterns have so apparently quickly woven historical viewpoint that we record these changing moods, reactions and realisations to the circumstances under which we are surviving. Many lessons can be learned if future generations pay attention.

While we all look forward to the hoped-for easing that vaccination will bring, there are still problems to overcome and difficulties to face. Just now, in early January, the rising number of cases of COVID-19, the speed of transmission and the pressure on hospitals of increasing numbers of admissions are combining to create what may yet prove to be the low point of the whole wretched business. What doesn't help is the advice that dental practices should remain open but that everyone should otherwise stay at home. A

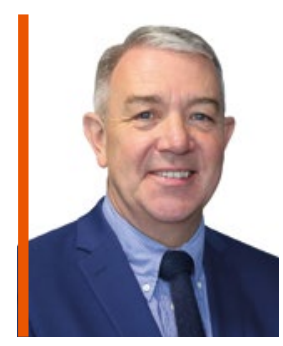

\section{'While we all look forward to the hoped- for easing that vaccination will bring, there are still problems to overcome and difficulties to face.'}

themselves into our collective and individual psyche. I was struck by this when reading the Opinion article in this issue on dental tourism. ${ }^{1}$ Researched and penned before the effects of the pandemic hit us all, the piece now reads almost like a slice of historical behavioural science. Seemingly, currently, of curiosity value, its messages will resonate once again with hope for the resumption of a more normal existence. The very notion of even getting on an aircraft is now a novelty, let alone doing so for the purposes of seeking dental treatment abroad; enough to contemplate travelling a few miles to the local surgery for whatever care can be mustered. What seemed unthinkable one year ago is now part of the accepted view of the world and I believe that it is important from a conundrum here somewhere. Common sense is required and will prevail, but the distress to lives, patients, livelihoods and businesses in the interim is substantial. Imagine, though, how much more catastrophic all this would seem without the salvation of vaccines.

So, in the meanwhile, we have to invoke the 'wartime spirit', roll up our sleeves in all senses of the saying and just get on with it. There is a sense of shared experience which does to some extent soften the blows, and once the storm has passed we will all be the stronger and wiser for having weathered it.

\section{References}

1. Ashiti S, Moshkun C. Dental tourists; treat, re-treat or do not treat. Br Dent J 2021; 230: 73-76.

https://doi.org/10.1038/s41415-021-2609-8 